\title{
Measurement of compartmental pressure in a leg by Whitesides method in a Nepalese patients attending a tertiary care hospital in eastern region of Nepal
}

\author{
P Chaudhary ${ }^{1}$, BP Shrestha ${ }^{1}$, DK Yadav ${ }^{2}$, GP Khanal ${ }^{1}$, R Rijal $^{1}$ \\ Department of Orthopaedics ${ }^{1}$, School of Public Health and Community Medicine ${ }^{2}$ \\ B.P. Koirala Institute of Health Sciences, Dharan, Nepal
}

\begin{abstract}
Background: Compartment syndrome can be a life or limb-threatening emergency. Early diagnosis is important for the prevention of disability. The clinical features are subjective in nature. Intra compartmental pressure measurement is a reliable objective method for early and accurate diagnosis of compartment syndrome. Objective: To measure the compartmental pressure in a leg by Whitesides method in Nepalese patient attending a tertiary care hospital in eastern region of Nepal. Methods: This is a cross-sectional study done over the period of three years on adult patients aged 16 years and above presenting to the Emergency Department of BPKIHS with unilateral closed tibial fracture. Total of 60 patients aged 16 years and above with closed fracture tibia were enrolled in the study. Results: Out of total study population, 40 were males and 20 females. The anterior compartmental pressure in the uninjured legs ranged between $3 \mathrm{mmHg}$ and $20 \mathrm{mmHg}$. Patients from hilly areas had more compartmental pressure (range 8 to $20 \mathrm{mmHg}$ ) as compared to patients of plain land (range 3 to $15 \mathrm{mmHg}$ ). People of hilly areas have more girth of thigh and calf muscles. Conclusion: The compartmental pressure in the uninjured legs ranged between $3 \mathrm{mmHg}$ and $20 \mathrm{mmHg}$ with variations in different geographic location. Whitesides injection technique of compartmental pressure measurement can be useful in the promptly defect compartmental syndrome in emergency and outpatient set-ups.
\end{abstract}

Keywords: Compartment pressure, whitesides, tibial fractures

\section{Introduction}

Compartment syndrome can be a life or limbthreatening emergency ${ }^{1}$. Early diagnosis is important for the prevention of disability.

\section{Address for correspondence}

Dr. Pashupati Chaudhary

Associate Professor

Department of Orthopaedics

E-mail: chaudharypashupati@yahoo.com
Approximately $40 \%$ of all compartment syndromes occur after fractures of the tibial shaft $^{2}$. The classical clinical features of five Ps (pain, pallor, paralysis, paraesthesia, pulselessness) cannot be always relied upon for early diagnosis of a developing acute 
compartment syndrome. ${ }^{3,4}$ These features are not apparent in most of the patients unless some permanent damage has occurred. Also, the clinical features are subjective in nature. Intra compartmental pressure measurement is a reliable objective method for early and accurate diagnosis of compartment syndrome. ${ }^{5-9}$

In Caucasians, the range of normal intracompartmental pressure of the leg is from $0 \mathrm{mmHg}$ to $15 \mathrm{mmHg}$. In the literature, such measurements have not been done in South Asian countries particularly in Nepal to identify normal leg intracompartmental pressures $^{2}$. We have sought to identify the normal range of pressures in such a population of Nepalese and to demonstrate the reproducibility of the Whitesides injection technique with materials that are easily available in most hospitals so that compartment syndromes could be identified promptly and inexpensively in developing countries. Though Whitesides injection technique is not an ideal one to measure the compartmental pressure but because of ease, easy availabily, it can be performed easily in OPD and casualy setup ${ }^{3}$. So, we performed the hospital-based prospective study at B.P. Koirala Institute of Health Sciences, Dharan, Nepal to measure the intracompartmental pressures in the anterior compartments of 20 uninjured legs of patients with closed contra lateral tibial fractures, at the time of presentation. The Whitesides infusion technique was used with the aim of determining the normal range of compartmental pressure in Nepal.

\section{Methods}

This was a prospective hospital-based study of the measurement of compartmental pressure in the legs of adults who presented to the emergency department of B.P. Koirala Institute of Health Sciences, Dharan, Nepal. The approval was obtained from the research committee of the Institute

Adult patients who were aged 16 years and above presenting to the emergency department of B.P.Koirala Institute of Health Sciences, Dharan, Nepal over a period of 3 years from 2006-2009 with unilateral closed tibial fractures. Consent was obtained for the measurement of normal compartmental pressures of anterior compartments of contra lateral uninjured legs of 60 patients with closed tibia fractures.

Patients with soft tissue injury to the contra lateral side of the fractured tibia, open fractures, neurovascular injury, and those patients who did not give consent were excluded from the study. The measurement was done using the Whiteside's' technique. ${ }^{10}$ The procedure was carried out under aseptic conditions with the patient supine taking all aseptic precaution. (Fig. 1a, b, c) 


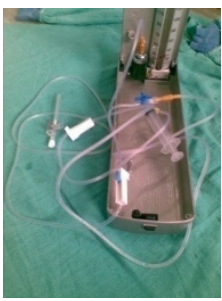

(a)

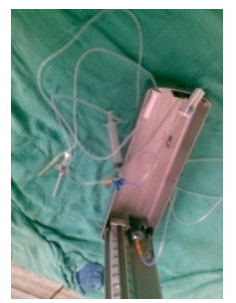

(b)

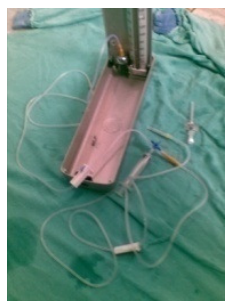

(c)
Fig. 1: Whitesides apparatus to measure compartment pressure

\section{Results}

There were 60 unilateral closed tibial fractures in which compartmental pressure was measured in normal limb (unfractured limb). The sex distribution and the age distribution of the studied population are shown in figure 2 and 3 respectively. The modes of injury are shown in figure 4.

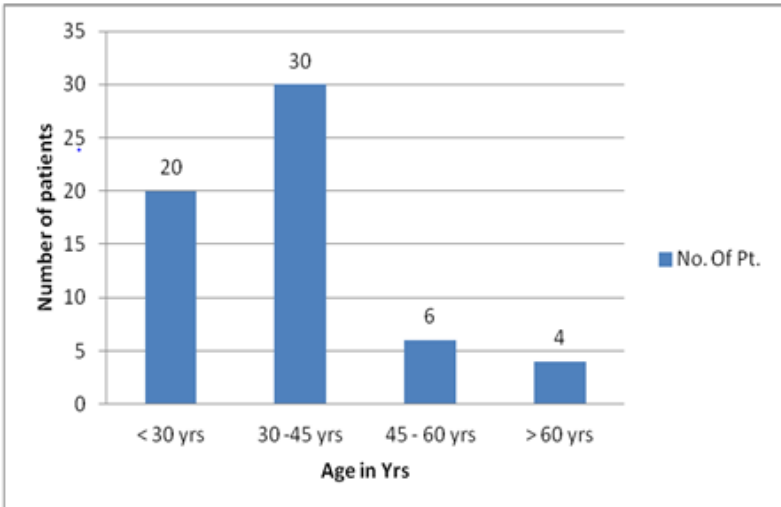

Fig. 2: Age distribution of subjects

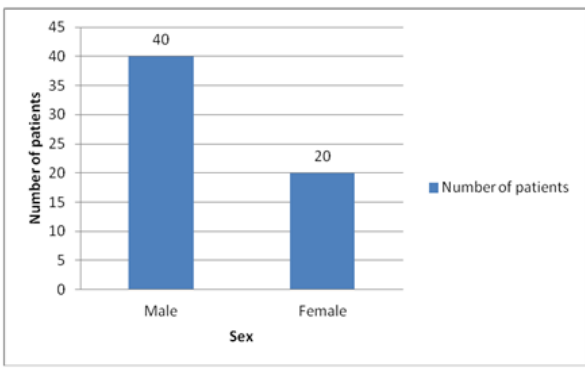

Fig. 3: Sex distribution

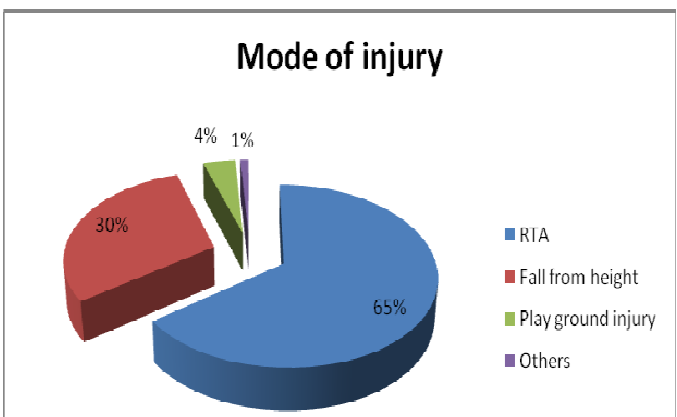

Fig. 4: Distribution of mode of injury

The anterior compartmental pressure in the uninjured legs ranged between $3 \mathrm{mmHg}$ and $20 \mathrm{mmHg}$. Patients from hilly areas had more compartmental pressure ranging from 8 to 20 $\mathrm{mmHg}$ as compared to patients of plain land, in which compartmental pressure ranged from 3 to $15 \mathrm{mmHg}$ (Fig 7). People of hilly areas have more girth of thigh and calf muscles. The average girth of thigh and calf muscles is more than $2 \mathrm{~cm}$ in people from hilly regions (Fig 8).

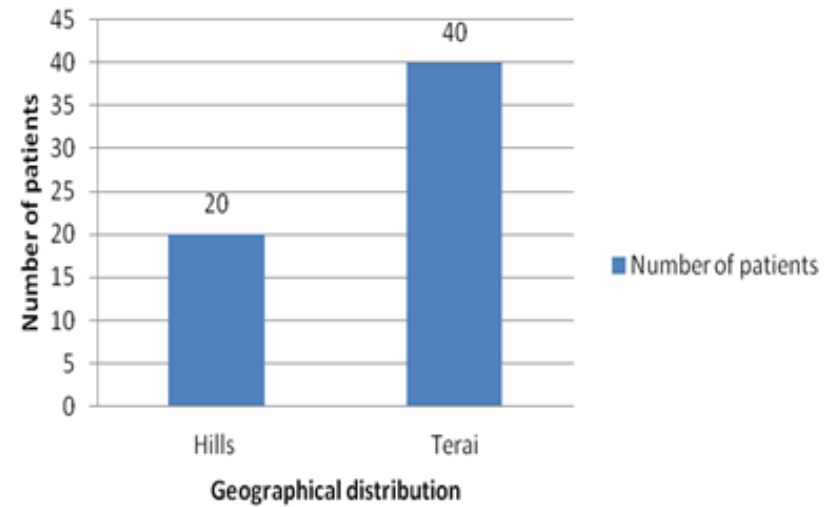

Fig. 5: Geographical distribution 


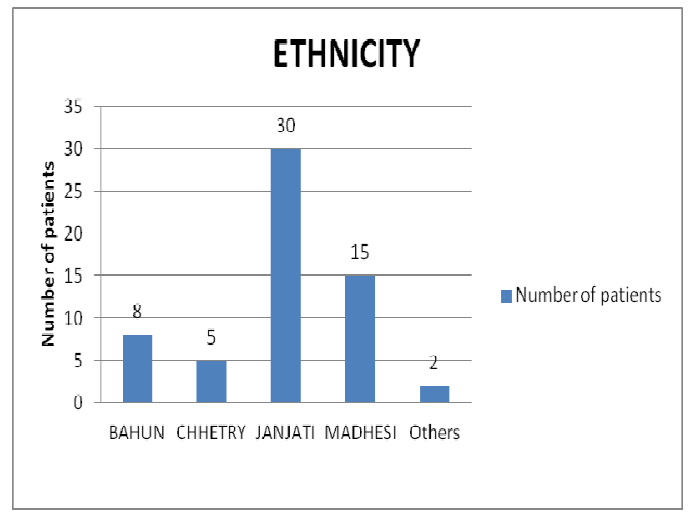

Fig. 6: Ethnic distribution of subjects

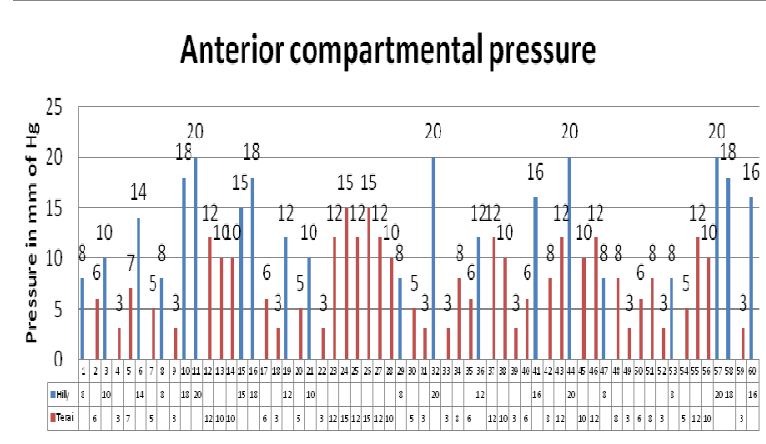

Fig. 7: Anterior compartmental pressure

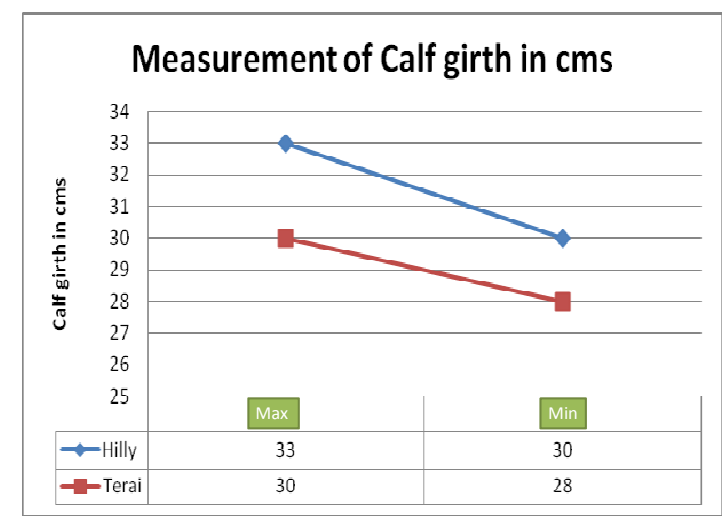

Fig. 8: Comparison of calf girth between Terai subjects and hill subjects

\section{Discussion}

The fascia compartments of the limbs have unyielding walls and contain compressible neurovascular structures. The leg has four compartments-anterior, lateral, superficial posterior and deep posterior. Among caucasians, both experimental and clinical experience has demonstrated that normal tissue pressures within closed compartments range between 0 to $15 \mathrm{mmHg}$. In caucasians, the range of normal intra compartmental pressure of the leg is from $0 \mathrm{mmHg}$ to15 $\mathrm{mmHg}$. In the literature, such measurements have not been done in South Asia to identify normal leg intra compartmental pressures. We have sought to identify the normal range of pressures in such a population of Nepalese, and to demonstrate the reproducibility of the Whitesides injection technique with materials that are easily available in most hospitals so that compartment syndromes could be identified promptly and inexpensively in developing countries.

Landerer in 1884 was the first person to measure the compartmental tissue pressures since then, many measurements done with different measurement techniques have been used to measure intracompartmental pressure. $^{9}$ In this study, the simple Whitesides injection technique was used. Though Whitesides injection technique is not an ideal one to measure the compartmental 
pressure but because of ease, easy availabily, it can be performed easily in OPD and casualy setup. Literature provides no data as to what constitutes the range of normal intracompartmental pressure in a Nepalese population which has a different goegraphic condition, people of different race, culture and living life styles. Although we think that they would be similar to data in Caucasian patients. The San Diego group reported that this value is less than 10 mmHg. 4, 6, 7 Puranen reported an average compartmental pressure of $15 \mathrm{mmHg}$ as the upper limit of normal. ${ }^{7}$ Matsen found the anterior compartmental pressure to be $11.5 \pm$ $0.5 \mathrm{mmHg}$ in seven normal limbs. ${ }^{9}$ Even though sophisticated and more modern equipment was used in determining the intra compartmental pressure in most of these other studies, the values obtained in this study using a simple Whiteside's infusion method fall within the previously reported range. Also, larger numbers of patients were studied in our group than the six or seven in the previously mentioned studies. Concerns have been raised that the Whiteside's method could generate falsely high pressure readings ${ }^{11}$, but Clayton evaluated this injection technique by applying known pressures to the extremities of six rabbits with a pneumatic cuff, showing a good linear correlation with a slope of $1.03(r=0.99)^{12}$

\section{Conclusion}

The average compartment pressure of Nepalese population ranges from $3 \mathrm{mmHg}$ and $20 \mathrm{mmHg}$, and it varies in people living in different geographic location. The measurement of compartmental pressure by Whitesides injection technique in Nepalese patients attending a tertiary care hospital in eastern region of Nepal, is that it can be used in developing countries to promptly detect compartmental syndrome in emergency department and even at out-patient set up.

\section{References}

1. Saikia KC, Bhattacharya TD, Agarwala V. Anterior compartment pressure measurement in closed fractures of leg. Indian J Orthop 2008; 42:217-21.

2. Moore KL. Clinically Oriented Anatomy. 3rd edition. Baltimore: Williams \& Wilkins; 1992. The Lower Limb; pp. 443-460.

3. Pellegrini VD, Jr, Reid S, Evants CM. Complication, Compartment Syndrome. In: Rockwood, Green, editors. Fractures in Adults. 4th edition. Vol. 1. Philadelphia: Lippincott-Raven; 1996. pp. 487-511.

4. Mubarak SJ, Owen CA, Hargens AR, Garetto LP, Akenson WH. Acute compartment syndrome diagnosis and treatment with the aid of the wick 
catheter. J Bone Joint Surg. (Am) 1978;60 (8):1091-1095

5. Mcdermott AGP, Marble AE, Yabsley $\mathrm{RH}$. Monitoring acute compartment pressure with the STIC catheter. Clin Orthop. 1984; 190:192-198.

6. Hargens AR, Romine JS, Spice JC, Evans KL, Mubarak SJ, Akenson WH. Peripheral nerve conduction block by high muscular compartment pressure. J Bone Joint Surg. (Am) 1979;61-A:192200

7. Mubarak SJ, Hergens AR, Owen CA, Garetto LP, Akenson WH. The Wick catheter technique of measurement of intramuscular pressure: A new research and clinical tool. J Bone Joint Surg. (Am) 1976; 58-A: 1016-1020.

8. Puranen J. The medial tibial syndrome in the medial fascial compartment of the leg. J Bone Joint Surg. (Br) 1974; 56-B (4):712-715.

9. Masten FA, Mayo KA, Sheridan GW, et al. Monitoring of intramuscular pressure. Surgery. 1976; 76 (6):702709.

10. Whitesides TE, Jr, Haney TC, Morimoto K, Harada K. Tissue pressure measurement as a determinant for the need of fasciotomy. Clin Orthop. 1975;113:43-51

11. Elliott KGB, Johnstone AJ. Diagnosing acute compartment syndrome. J Bone Joint Surg. (Br) 2003; 85-B (5):625632.

12. Clayton JM, Hayes AC, Barnes RW. Tissue pressure in perfusion in compartment syndrome. J Surg Res. 1977;22:333-339 